\title{
Factors Affecting Fertility Decision-Making Among Transgender Adolescents and Young Adults
}

\author{
Diane Chen, PhD, ${ }^{1-4}$ Moira A. Kyweluk, MA, ${ }^{5,6}$ Afiya Sajwani, ${ }^{1}$ Elisa J. Gordon, PhD, MPH, ${ }^{7-9}$ \\ Emilie K. Johnson, MD, MPH, ${ }^{8,10,11}$ Courtney A. Finlayson, MD, ${ }^{4,12}$ and Teresa K. Woodruff, PhD $^{13,14}$
}

\begin{abstract}
Purpose: This study aimed to identify factors affecting transgender adolescents' and young adults' (AYA) decisions to pursue fertility preservation (FP).

Methods: Participants completed a semistructured interview between December 2016 and June 2017 to inform improvements in fertility counseling and the development of a fertility decision aid targeted to transgender youth. Interviews included open-ended questions within the following domains: (1) gender-affirming medical care received, (2) knowledge of gender-affirming hormone effects on fertility and FP options, (3) FP decision-making, and (4) how, when, and what information AYA prefer to receive regarding FP. The interviews were analyzed thematically.

Results: Eighteen transgender AYA (ages 15-24) participated (60\% participation rate). The majority was White $(61 \%)$ and assigned female at birth (67\%). Half received specialized FP counseling (50\%). Few of the transgender AYA pursued FP (33\%). Five key themes reflecting factors affecting transgender AYA's FP decision-making were identified: (1) future parenthood desires, (2) individual experiences of gender dysphoria, (3) family values around biological parenthood, (4) financial considerations, and (5) fertility information provision.

Conclusions: Transgender AYA consider numerous factors in deciding whether to pursue FP. Although individual desires for and family values around biological parenthood influenced whether AYA pursued specialized FP counseling, individual experiences of gender dysphoria and costs of FP were barriers. AYA also identified shortcomings in fertility counseling with providers, highlighting the need to establish standardized counseling protocols and develop patient decision aids.
\end{abstract}

Keywords: gamete cryopreservation, gender dysphoria, oocyte cryopreservation, qualitative research, reproductive health, sperm cryopreservation

\section{Introduction}

T RANSGENDER ADOLESCENTS AND young adults (AYA) increasingly seek medical care to reduce gender dysphoria. ${ }^{1}$ Treatment with gender-affirming hormones (GAH; tes- tosterone or estrogen) induces sex steroid-mediated pubertal changes (e.g., facial hair growth, voice deepening, or breast development). GAH treatment is associated with improved psychosocial functioning ${ }^{2}$; however, some studies suggest that exogenous hormones have a negative impact on fertility. 3,4

\footnotetext{
${ }^{1}$ The Potocsnak Family Division of Adolescent and Young Adult Medicine, Ann \& Robert H. Lurie Children's Hospital of Chicago, Chicago, Illinois.

${ }^{2}$ Department of Child and Adolescent Psychiatry, Ann \& Robert H. Lurie Children's Hospital of Chicago, Chicago, Illinois.

${ }^{3}$ Department of Psychiatry and Behavioral Sciences, Northwestern University Feinberg School of Medicine, Chicago, Illinois.

${ }^{4}$ Department of Pediatrics, Northwestern University Feinberg School of Medicine, Chicago, Illinois.

${ }^{5}$ Department of Anthropology, Northwestern University, Chicago, Illinois.

${ }^{6}$ Program in Public Health, Northwestern University Feinberg School of Medicine, Chicago, Illinois.

${ }^{7}$ Division of Transplantation, Department of Surgery, Northwestern University Feinberg School of Medicine, Chicago, Illinois.

${ }^{8}$ Center for Healthcare Studies, Northwestern University Feinberg School of Medicine, Chicago, Illinois.

${ }^{9}$ Center for Bioethics and Medical Humanities, Northwestern University Feinberg School of Medicine, Chicago, Illinois.

${ }^{10}$ Division of Urology, Ann \& Robert H. Lurie Children's Hospital of Chicago, Chicago, Illinois.

${ }^{11}$ Department of Urology, Northwestern University Feinberg School of Medicine, Chicago, Illinois.

${ }^{12}$ Division of Endocrinology, Ann \& Robert H. Lurie Children's Hospital of Chicago, Chicago, Illinois.

${ }_{13}^{13}$ Department of Obstetrics and Gynecology, Northwestern University Feinberg School of Medicine, Chicago, Illinois.

${ }^{14}$ Division of Reproductive Science in Medicine, Northwestern University Feinberg School of Medicine, Chicago, Illinois.
} 
Established fertility preservation (FP) methods exist for postpubertal birth-assigned males (sperm cryopreservation) and postmenarchal birth-assigned females (oocyte cryopreservation). ${ }^{5-7}$ Thus, practice guidelines published by the World Professional Association for Transgender Health, ${ }^{8}$ the Endocrine Society, ${ }^{9}$ and the American Society for Reproductive Medicine ${ }^{10}$ recommend fertility counseling before GAH initiation.

Infertility causes psychosocial distress among affected adults. ${ }^{11}$ Pediatric cancer survivors, a population for whom medical treatment is known to cause infertility, express disappointment, regret, and anger about missed opportunities for FP. ${ }^{12,13}$ To date, two studies have examined FP rates in transgender AYA, with $3 \%$ of $72 \mathrm{AYA}^{14}$ and $4.8 \%$ of 105 AYA $^{15}$ cryopreserving gametes. Low FP rates in transgender AYA contrast with their higher rates of reported desires for biological children, which ranged from $24 \%$ to $36 \%$ across two studies. ${ }^{16,17}$

The discrepancy between reported desires for biological children and rates of FP suggests that transgender AYA may be at risk for distress and regret should they learn they are infertile in adulthood. Retrospective chart reviews have identified cost, invasiveness of FP procedures, reluctance to delay GAH, and plans to adopt children as reasons that transgender AYA decline FP. ${ }^{14,15}$ However, a comprehensive examination of fertility-related decision-making in transgender AYA has yet to be explored empirically. This study aimed to identify factors that affect transgender AYA's decisions to pursue FP.

\section{Methods}

\section{Recruitment and sampling}

Self-identified transgender AYA ages 14-24 interested in or receiving GAH were eligible to participate in the study. Participants were recruited from a subspecialty pediatric gender clinic located in a large Midwestern city through clinician referral and from community-based organizations serving transgender AYA using study flyers. We purposively sampled for AYA with varying personal experiences with FP counseling and procedures (i.e., completed FP, received specialized FP counseling from a fertility specialist but did not pursue FP, and neither received specialized FP counseling nor completed FP) and for non-White and birth-assigned male participants to diversify respondent characteristics. Transgender AYA were approached in person or contacted by telephone and invited to participate. Participants aged 18 and over provided written informed consent; those under age 18 provided written assent while a parent gave written permission. Although not an exclusionary criteria, none of the participants had received pubertal suppression treatment. All procedures were approved by the Ann \& Robert H. Lurie Children's Hospital of Chicago's Institutional Review Board.

\section{Procedures}

Participants completed an in-person, semistructured interview between December 2016 and June 2017. Interviews assessed fertility decision-making, with the intention of improving fertility counseling and developing a fertility decision aid targeted to transgender AYA. Interviews included open-ended questions within the following domains: (1) gender-affirming medical care received, (2) knowledge of GAH effects on fertility and FP options, (3) FP decisionmaking, and (4) how, when, and what information AYA prefer to receive regarding FP. Participants also completed a questionnaire documenting their age, birth-assigned sex, race/ethnicity, and educational attainment, whether they were currently or previously receiving pubertal suppression treatment or GAH, whether they have tried to have biological children, pursued FP procedures (e.g., oocyte or sperm cryopreservation) or used any assisted reproductive technologies to attempt to have a child, and one question: "Which statement best describes how you feel about having children someday?"

Interviews were conducted by a trained research assistant using an interview guide adapted from a study exploring attitudes toward FP in another patient population. ${ }^{18}$ Before participant recruitment, the interviewer and the principal investigator conducted pilot interviews for training purposes, to assess interview length and ensure the interview guide was comprehensive. Interviews were audio recorded and lasted an average of 65 minutes, and participants received a $\$ 25$ gift card. Full details regarding study procedures are reported elsewhere. ${ }^{19}$

\section{Data management and analysis}

Interviews were transcribed verbatim. Transcripts were uploaded to Dedoose, ${ }^{20}$ an Internet-based qualitative analysis software program. We used thematic analysis ${ }^{21}$ to identify themes related to fertility decision-making in transgender AYA and followed published standards for reporting qualitative research. 22

The coding team included M.A.K., a White queeridentified cisgender woman, doctoral candidate in Anthropology, and D.C., an Asian American cisgender heterosexual woman, licensed clinical psychologist with expertise in transgender health. Coders independently reviewed sets of three to five interviews and identified preliminary themes based on whether they represented a meaningful pattern in the data. Themes were refined through constant comparison, discussion, and consensus. ${ }^{23}$ Once consensus was reached, and as an additional method of reducing bias, the coding pair repeated the consensus-building process for the first two sets of interviews with a third coder, A.S. (a South Asian queer-identified gender fluid research assistant with a bachelor's degree in psychology) who provided feedback.

The coding team met weekly to establish consensus and resolve coding discrepancies. Analytic phases were repeated until all available data were coded at least once, until all coding discrepancies were resolved, and reaching saturationwhen novel codes no longer emerged. Thereafter, reliability testing was performed on a subset of excerpts. The pooled Kappas were 0.91 (13 excerpts), indicating excellent interrater reliability. ${ }^{24}$

Cross-case analyses were conducted using Fisher's exact tests to examine whether there were significant patterns in identified themes based on participants' birth-assigned sex and FP consult and completion status.

\section{Results \\ Participant characteristics}

A total of 33 AYA were eligible for recruitment; 30 were contacted, 21 enrolled, and 3 failed to present for their 
research visit (60\% participation rate). The sample consisted of 18 AYA ages 15 to 24 (mean $=18.4$, standard deviation $=2.3$ ). The majority was White $(61 \%)$ and assigned female at birth $(67 \%)$ (Table 1). Few of the transgender AYA pursued FP $(33 \%)$, although a larger percentage of birthassigned males (67\%) than birth-assigned females (16\%) had completed FP. There were no significant differences in age, race/ethnicity, or assigned sex at birth between study participants and eligible but not enrolled youth. Table 2 presents individual characteristics for each participant. Table 3 depicts youths' responses to the question about how they feel about having children someday.

\section{Qualitative analyses}

Five key themes reflecting factors affecting transgender AYA's FP decision-making were identified: (1) future parenthood desires, (2) individual experiences of gender dysphoria, (3) family values around biological parenthood, (4) financial considerations, and (5) fertility information provision. All key themes and examples are summarized in Table 4.

Future parenthood desires. AYA varied in desires for parenthood, affecting decisions to pursue FP consultation and procedures. Some youth explicitly desired biological children and expressed interest in FP: 'I've always wanted kids. And so...we talked to someone here about freezing eggs" (S113, 17-year old, on testosterone, received FP consult, no FP). Other AYA did not want children, biological or otherwise: "I' $m$ not interested in having children of any sort, be it through adoption or reproduction" (S107, 20-year old, on estrogen, no FP consult, no FP). Some participants expressed

Table 1. Participant Characteristics $(N=18)$

\begin{tabular}{lc}
\hline & $\mathrm{n}(\%)$ or $\mathrm{M} \pm \mathrm{SD}$ \\
\hline Age in years & $18.4 \pm 2.3$ \\
Assigned sex at birth & $12(66.7)$ \\
Female & $6(33.3)$ \\
Male & \\
Race & $11(61.1)$ \\
White & $4(22.2)$ \\
Black/African American & $1(5.6)$ \\
Asian & $2(11.1)$ \\
Multiracial & \\
Ethnicity & $17(94.4)$ \\
Not Spanish/Hispanic/Latinx origin & $1(5.6)$ \\
Spanish/Hispanic/Latinx origin & \\
Highest educational attainment & $1(5.6)$ \\
9th Grade & $2(11.1)$ \\
10th Grade & $3(16.7)$ \\
11th Grade & $6(33.3)$ \\
High school diploma/GED & $6(33.3)$ \\
Some college/technical school & \\
$\quad$ or associate's degree & $14.7 \pm 15.5$ \\
Duration on GAH in months & \\
\hline
\end{tabular}

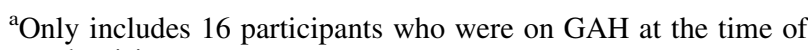
the study visit.

GAH, gender-affirming hormones; GED, General Education Diploma; M, mean; SD, standard deviation.
}

uncertainty about parenthood desires, which complicated decision-making:

\begin{abstract}
"With fertility, it was a very back and forth of just, do I want to leave this option open to myself or am I willing to just kind of close that door? And it was a couple months of thought of just, do you want to be able to have your own biological children? Do you not? And it just came to the point where I was like, you don't even know if you want kids, and if you decide to, there's thousands, millions... of kids who are there to be adopted" (S111, 17-year old, on testosterone, received FP consult, no FP).
\end{abstract}

AYA interested in parenting also took into account potential co-parenting partners in FP decision-making:

\begin{abstract}
"I did save sperm [but] I probably plan on adopting just because the people who I think I'll be in a long-term relationship with are people who either probably wouldn't be able to carry a child in their uterus or who wouldn't want to carry a child in their uterus" (S116, 18-year old, on estrogen, received FP consult, completed FP).
\end{abstract}

Individual experiences of gender dysphoria. AYA's personal experiences of gender dysphoria affected their decisions not to pursue FP, even among those desiring biological children in the future. Some youth expressed concerns about the mental health ramifications of delaying GAH treatment to complete FP:

\begin{abstract}
"I was thinking, yeah, this is smart, why don't I save my eggs. But then at the same time it was just....an ongoing battle internally with myself and my gender identity...I was just super depressed...They told me if you want to do it [FP], you'll have to wait on hormones...it does kind of make me sad, a little bit, because I'm just like, well, I should have saved it [eggs]. But I don't think I would have made it, because I was just going through so much...I had very bad thoughts. And like I said, testosterone literally saved my life" (S105, 18-year old, on testosterone, received FP consult, declined FP).
\end{abstract}

Trans masculine participants referenced dysphoria stemming from the ovarian stimulating hormones necessary for FP:

\begin{abstract}
"I know the moment that I heard that I would have to go on [ovarian stimulating hormone for FP]...I was like yeah, no. I'm out...I just felt like that was going backwards, and I didn't want to...so that was definitely something that played into [my decision]" (S111, 17-year old, on testosterone, received FP consult, declined FP).
\end{abstract}

Family values around biological parenthood. AYA had varying perceptions of familial expectations or felt pressure to have biological children, which shaped FP decisionmaking. Some youth perceived no pressure to preserve fertility. Among these AYA, some chose not to pursue FP: "I don't think they [parents] really care, they just want me to be happy...they're not like "you need to give us grandchildren", (S107, 20-year old, on estrogen, no FP consult, no FP). However, others chose to preserve gametes: "My mom said...the importance of having a genetically related child is only as 


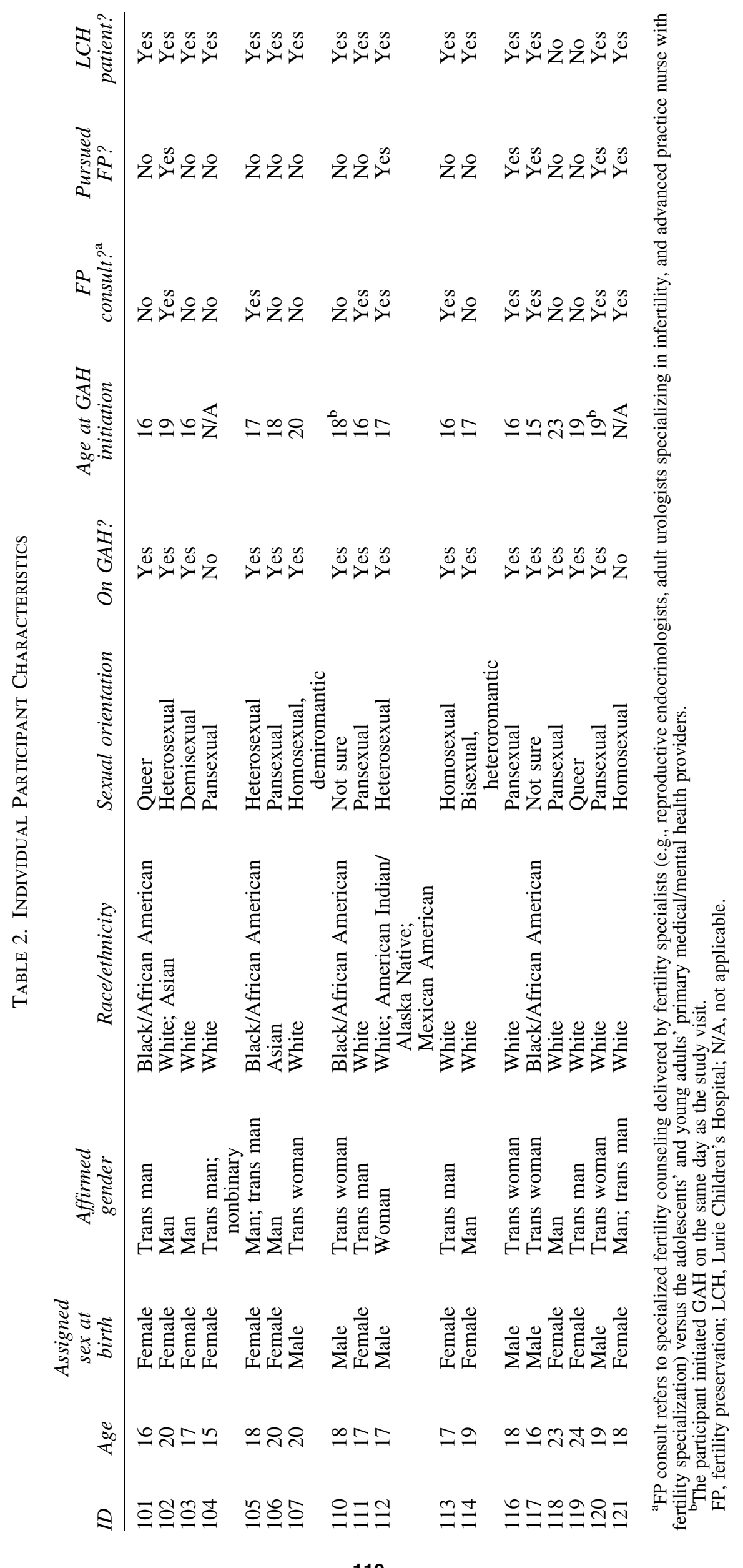


Table 3. Participant Responses to "Which

Statement Best Describes How You Feel

About Having Children Someday

(Circle All That Apply)?'” Grouped

by Fertility Preservation Status

\begin{tabular}{|c|c|c|c|}
\hline Response options & $\begin{array}{c}\text { No } \\
\text { FP } \\
\text { consult, } \mathrm{n}\end{array}$ & $\begin{array}{c}\text { FP } \\
\text { consult } \\
\text { only, } \mathrm{n}\end{array}$ & $\begin{array}{c}\text { FP } \\
\text { consult } \\
\text { and } \\
\text { pursued } \\
\text { FP, n }\end{array}$ \\
\hline $\begin{array}{l}\text { I do not plan to have } \\
\text { children }\end{array}$ & 2 & 0 & 0 \\
\hline $\begin{array}{l}\text { I am not sure if } \\
\text { I plan to have children }\end{array}$ & 3 & 1 & 3 \\
\hline I plan to adopt children & 3 & 1 & 2 \\
\hline $\begin{array}{l}\text { I plan to have children } \\
\text { by surrogacy } \\
\text { (egg or sperm donor) }\end{array}$ & 2 & 1 & 1 \\
\hline $\begin{array}{l}\text { If I choose to have children, } \\
\text { I will probably need } \\
\text { medical help }\end{array}$ & 1 & 1 & 2 \\
\hline $\begin{array}{l}\text { If I choose to have children, } \\
\text { I will probably not } \\
\text { need medical help }\end{array}$ & 0 & 0 & 0 \\
\hline $\begin{array}{l}\text { If I choose to have children, } \\
\text { I am not sure whether } \\
\text { I will need medical help }\end{array}$ & 1 & 0 & 2 \\
\hline Other & 1 & 0 & 0 \\
\hline
\end{tabular}

FP consult refers to specialized counseling delivered by fertility specialists (e.g., reproductive endocrinologists, adult urologists specializing in infertility, and advanced practice nurse specializing in fertility) versus the adolescents' and young adults' primary medical/mental health providers.

important to them as it was important to me" (S117, 16-year old, on estrogen, received FP consult, completed FP).

Other participants, however, perceived more pressure from parents, influencing decisions to complete FP: "My mother was really wanting me to have a kid...I wasn't really asking her, but she was giving me her insight of the whole situation. And she was all for it [FP]. She really wanted me to do it" (S112, 17-year old, on estrogen, received FP consult, completed FP). Similarly, another participant shared: "My mom was basically like I don't want you to [start testosterone] until we have an actual plan on your eggs" (S104, 15-year old, not on testosterone, no FP consult, no FP). Another participant stated:

\footnotetext{
"[Fertility] is kind of a concern for them. [My parents] were worried, 'Oh, what if she changed her mind.' Maybe that's part of the reason they wanted me to save sperm...it's just there in case I ever wanted to use it" (S116, 18-year old, on estrogen, received FP consult, completed FP).
}

Financial considerations. Almost all of the participants referenced financial considerations in decision-making and the importance of counseling around costs. One participant shared: "The most important is being aware of costs. [It's] very important and does pertain to a decision [about FP]" (S106, 20-year old, on testosterone, no FP consult, no FP). Some AYA desired, but were unable to pursue FP due to cost: "I'd be like, you know what, I will not be doing [hormones] without freezing my sperm so I can have a biological child of my own if financial issues weren't in play"' ( $\mathrm{S} 110$, 18-year old, on estrogen, no FP consult, no FP). Other participants highlighted the potential for emotional distress if FP is desired but unattainable due to costs: "You don't want to bring someone's hopes up and then crash them down...it' $d$ be pointless to get their hopes up and then find out they won't be able to afford it cause it's just worse for them" (S104, 15-year old, not on testosterone, no FP consult, no FP).

Fertility information provision. All participants reported that their primary medical/mental health team discussed fertility risks, with a subset pursuing counseling with fertility specialists. However, there was variability in perceived adequacy of fertility counseling, at times hindering FP decisionmaking. Some youth felt that counseling was effective in supporting decision-making:

\begin{abstract}
"I wasn't totally certain about whether or not I was going to go through with the process. But the information that she was able to provide...the rundown of what's necessary, the tests that needed to be done, and the costs was enough to help me make that decision. It was pretty much everything I needed to confirm whether or not this was something that I wanted to do" (S120, 19-year old, on estrogen, received FP consult, completed FP).
\end{abstract}

Other participants felt that fertility information provision was incomplete or lacking, which affected decision-making satisfaction:

\begin{abstract}
"I just sometimes wish I had more information about certain things. Like I said, I do kind of regret not doing the fertility thing [FP]...I felt like if I didn't do my own research, and I didn't know, hey, I can be on testosterone then get off, and then I can just like start taking ovulation medication...like imagine if I didn't do my own research! I just wish they had told me, 'hey, there is a way, even after you start testosterone to do [FP]'" (S105, 18-year old, on testosterone, received FP consult, no FP).
\end{abstract}

\section{Cross-case analyses}

Fisher's exact tests showed no significant patterns in identified themes between (1) birth-assigned males and females, (2) those who pursued FP consultation versus those who did not, or (3) those who completed FP versus those who did not.

\section{Discussion}

This study identified factors affecting fertility-related decision-making among transgender AYA with varying personal experiences of fertility counseling and FP. Our findings suggest that transgender AYA consider myriad factors in weighing whether to pursue FP. Desires for parenthood influenced whether AYA pursued specialized FP counseling beyond fertility discussions with the primary medical/mental health team. However, even among AYA desiring biological parenthood and FP, individual experiences of gender dysphoria weighed into decisions not to complete FP, particularly among trans masculine AYA. These barriers are consistent 


\begin{tabular}{|c|c|c|}
\hline Key theme & Definition & Example \\
\hline $\begin{array}{l}\text { Future parenthood } \\
\text { desires }(n=18)\end{array}$ & $\begin{array}{l}\text { Youth's current desire for or lack of desire for } \\
\text { children, including biological parenthood } \\
\text { and other parenting options (adoption, } \\
\text { surrogacy, donor gametes, etc.) }\end{array}$ & $\begin{array}{l}\text { "I don't know if I want children, if I want children I } \\
\text { would probably adopt. I've just never really been } \\
\text { interested in having my own child really. There's } \\
\text { nothing wrong with it, I'm just not interested in it." } \\
\text { (S101, 16-year old, on testosterone, no FP consult, } \\
\text { no FP) } \\
\text { "I'm grateful that I can have a biological child whether } \\
\text { we... whether my future spouse and I have it through a } \\
\text { surrogate or she carries it." (S102, 20-year old, on } \\
\text { testosterone, received FP consult, completed FP) }\end{array}$ \\
\hline $\begin{array}{l}\text { Individual } \\
\text { experiences of } \\
\text { gender dysphoria } \\
(n=9)\end{array}$ & $\begin{array}{l}\text { Gender incongruence affects desire for FP or } \\
\text { pursuit of FP; FP emphasizes assigned sex at } \\
\text { birth }\end{array}$ & $\begin{array}{l}\text { "For me personally... as someone who identifies as male, } \\
\text { [having children] is just not something that resonates } \\
\text { with me either. In terms of having a biological child, it } \\
\text { just does not mean anything to me. Especially because } \\
\text { I understand that while I was assigned female at birth, } \\
\text { I don't necessarily consider my body in that way. And } \\
\text { I do my best to adjust the way that I see my body to } \\
\text { the way I identify as male." (S106, 20-year old, on } \\
\text { testosterone, no FP consult, no FP) } \\
\text { "[FP] was awkward I guess. And, I don't know, just kind } \\
\text { of against my gender identity... so it was kind of...it } \\
\text { was a very interesting experience. I wasn't the most } \\
\text { happy camper, but I knew I needed to know the stuff } \\
\text { [about FP] so then I can get that done with and then } \\
\text { move on." (S121, 18-year old, not on testosterone, } \\
\text { received FP consult, completed FP) }\end{array}$ \\
\hline $\begin{array}{l}\text { Family values around } \\
\text { biological } \\
\text { parenthood }(n=15)\end{array}$ & $\begin{array}{l}\text { Youths' perceptions of parent/family values } \\
\text { around youth having biological children in } \\
\text { the future }\end{array}$ & $\begin{array}{l}\text { "I've talked about [biological parenthood] a lot with my } \\
\text { mom, she clearly wants grandkids, that's all she wants. } \\
\text { Not-not all she wants, but she really wants them. } \\
\text { I know my dad doesn't care that much whether we } \\
\text { have kids or not but my mom...I've talked to her a lot } \\
\text { about it. And she never cared whether they were } \\
\text { biological or not in the first place." (S103, 17-year } \\
\text { old, on testosterone, no FP consult, no FP) } \\
\text { "[Biological parenthood] is something that they like to } \\
\text { put a lot of stress on...my mother...tells me all the time } \\
\text { that...you can't replicate the bond that you'd have with } \\
\text { a child that is genetically yours." (S120, 19-year old, } \\
\text { on estrogen, received FP consult, completed FP) }\end{array}$ \\
\hline $\begin{array}{l}\text { Financial } \\
\quad \text { considerations } \\
\quad(n=15)\end{array}$ & $\begin{array}{l}\text { Costs of procedures are a major factor in } \\
\text { decision-making about FP }\end{array}$ & $\begin{array}{l}\text { "So we came to the conclusion [about FP] by talking, } \\
\text { and talking a lot about costs and talking about benefits } \\
\text { of [FP], but also a lot of times of cost." (S117, 16-year } \\
\text { old, on estrogen, received FP consult, completed FP) } \\
\text { "And the biggest decision factor for me was cost. } \\
\text { I absolutely had no idea how much [FP] was going to } \\
\text { cost." (S120, 19-year old, on estrogen, received FP } \\
\text { consult, completed FP) }\end{array}$ \\
\hline $\begin{array}{l}\text { Fertility information } \\
\text { provision }(n=18)\end{array}$ & $\begin{array}{l}\text { Degree to which clinicians provide adequate } \\
\text { and accurate information about fertility and } \\
\text { FP procedures and effective counseling to } \\
\text { youth }\end{array}$ & $\begin{array}{l}\text { "I mean, it was kind of like some of it was new } \\
\text { information [about FP], but my mom kind of knew } \\
\text { about the options that are available. Yeah. I mean, I } \\
\text { think it was fine.... lot of information, but...I think it } \\
\text { was all presented very-it was clear, and we all kind } \\
\text { of understood it. It was definitely helpful. Cause I } \\
\text { wasn't totally sure whether [FP] was right for me or } \\
\text { not, but getting the information definitely helped." } \\
\text { (S113, 17-year old, on testosterone, received FP } \\
\text { consult, no FP) } \\
\text { "I don't know a lot [about FP] I was not told that much at } \\
\text { all [by clinicians]... Apparently there is just not } \\
\text { enough information, at least when I started } \\
\text { [testosterone] two years ago. I was told that } \\
\text { [testosterone] could influence fertility in some way, but } \\
\text { it was just not...there was no straight answer." (S106, } \\
\text { 20-year old, on testosterone, no FP consult, no FP) }\end{array}$ \\
\hline
\end{tabular}


with those reported by transgender AYA from retrospective chart reviews ${ }^{14,15}$ and a recent case study. ${ }^{25}$

Family values around parenting also influenced AYA's decisions to pursue FP consultation and FP. For example, three trans feminine youth who indicated that they were "not sure" if they plan to have children actually completed FP. Two of these participants specifically referenced parental pressure to cryopreserve sperm. Parental pressure to complete FP represents an ethical dilemma as it may interfere with youth autonomy to make reproductive health decisions. ${ }^{26}$ Fertility counseling should thus include support navigating complex discussions about personal parenting values and priorities among AYA and their parents.

Similar to the oncology population, ${ }^{27}$ cost was a significant barrier to FP, with several AYA indicating that they would have cryopreserved gametes if not for limited financial resources. In the United States, the average cost of ovarian stimulation and oocyte retrieval is $\$ 12,737,{ }^{28}$ and for sperm retrieval by masturbatory emission it is $\$ 745^{29}$ Long-term annual storage fees average $\$ 343 .{ }^{30}$ Costs render FP out of reach for many transgender AYA. Since 2017, five states (Connecticut, Delaware, Illinois, Maryland, and Rhode Island) have enacted insurance laws requiring state-based insurers to subsidize costs of FP for patients who face infertility secondary to medically necessary treatments. The impact of this new legislation on transgender individuals seeking gender-affirming, but potentially fertility-compromising, treatments is unclear. It is imperative that providers of transgender health care stay abreast of evolving state-level insurance coverage policies to advocate for insurance subsidies on behalf of transgender patients who may desire FP.

Understanding factors influencing FP decision-making is critical as transgender youth are seeking transition-related medical care at younger ages. With clinical practice guidelines recommending fertility counseling before starting $\mathrm{GAH},{ }^{8-10}$ transgender AYA must consider medical decisions that may have long-term reproductive health implications during a period in which thinking about fertility and parenting is developmentally non-normative. This puts transgender AYA at risk for prioritizing gender-affirming treatments over fertility at a time in their lives when their parenthood goals may not be well defined, which may be problematic as impaired fertility affects future quality of life, rather than current functioning. ${ }^{13,31}$

Participants highlighted many ways in which fertility counseling could be improved, including more in-depth discussions about fertility and FP, and ongoing conversations over time even after GAH initiation. Another important finding is that all AYA in our study expressed the belief that GAH exert a negative impact on fertility and reproductive functioning. Unlike pediatric oncology, which presents quantifiable risks to fertility resulting from chemotherapy and radiation treatment, little is known about fertility-related outcomes after long-term GAH treatment in transgender populations. For instance, both planned and unintended pregnancies have been reported in transgender men with previous and current use of testosterone. ${ }^{32-34}$ In addition, variability in testicular histology has been observed among transgender women undergoing gender-affirming orchiectomy. ${ }^{35}$ Thus, fertility counseling for transgender AYA typically is about the unknown risks of GAH on long-term fertility. Lack of clarity about the impact of GAH on fertility, ${ }^{7}$ and reversibil- ity of any fertility impairment complicates fertility counseling. Basic science research is needed to more clearly define hormone-specific risks (i.e., testosterone-specific effects on ovarian function and estrogen-specific effects on testicular function) and dose-specific risks of GAH on fertility. In addition, counseling should include education that GAH are not effective as contraception. ${ }^{34}$ Moreover, given that a third of our participants expressed interest in adopting children in the future, fertility counseling should include discussions of all possible pathways to parenting, including adoption and its associated costs.

Our sample was comprised of transgender AYA who had not received pubertal suppression treatment before GAH, and thus had progressed far enough through their endogenous puberty to have mature gametes for FP. Transgender youth are presenting at younger ages for care. ${ }^{36}$ Increasingly, these youth will be eligible for pubertal suppression treatment in early puberty, which halts undesired pubertal changes and prevents gamete maturation. ${ }^{9}$ No studies to date address whether fertility is possible among transgender people treated with pubertal suppression followed directly by $\mathrm{GAH}^{7}$

\section{Strengths and limitations}

Our study has several strengths. First, in-depth qualitative analyses enriched our current understanding about fertility decision-making in transgender youth. In addition, our recruitment strategy allowed us to examine decision-making factors in a diverse sample of transgender AYA that varied in experience with fertility counseling and FP. Our study also has limitations to acknowledge. All but two participants were recruited from the same clinic, a gender-affirming multidisciplinary program housed in an institution with an established pediatric FP program. Providers caring for these AYA are likely to be more attuned to fertility considerations, potentially limiting generalizability to AYA receiving care in community-based settings. Participants also varied in their medical transitions. Future studies should examine decisionmaking processes in real time.

\section{Conclusion}

These study findings suggest that transgender AYA consider many factors in making decisions to pursue FP and highlight the need to improve fertility counseling for this vulnerable population, consistent with a recent call to action to improve fertility counseling in pediatrics more generally. ${ }^{37}$ Ongoing attention to strategies that support patient education and decision-making, including the development of patient education and decision-support tools and evaluating the impact of these decision aids on care delivery, remain important next steps in this research. Future studies also should examine whether transgender adults of childbearing age who were offered FP but declined, experience regret related to their FP decisions.

\section{Acknowledgments}

This study was supported by the 2016-2017 Research Excellence Award by the Chairman from the Department of Psychiatry and Behavioral Sciences, Northwestern University Feinberg School of Medicine (principal investigator [PI]: Chen); the 2017 Targeted Research Grant from the 
Society of Pediatric Psychology (PI: Chen); and the 2017 Sexualities Project at Northwestern Summer Grant Award (PI: Kyweluk). Dr. Chen's effort also was supported, in part, by R01HD082554, R21HD087839, and R21HD097459 from the Eunice Kennedy Shriver National Institute of Child Health and Human Development. Study sponsors had no role in the (1) study design; (2) collection, analysis, and interpretation of data; (3) writing of the article; or (4) the decision to submit the article for publication.

We thank all of the participants for their thoughtful contributions in the interviews. We also thank Rob Garofalo for his leadership within the Gender \& Sex Development Program that made this research possible; Marco Hidalgo, Jennifer Jensen, Ginny Scheffler, Lisa Simons, and D. Javier Thompson for their assistance in recruiting study participants; and Ilina Rosoklija and Anthony D'Oro for their feedback on our interview guide.

\section{Disclaimer}

The content is solely the responsibility of the authors and does not necessarily represent the official views of the National Institutes of Health. Participant interviews were analyzed previously from an anthropological perspective for a student project exploring whether currently available FP technologies adequately address transgender AYA's imagined parenthood futures.

\section{Author Disclosure Statement}

No competing financial interests exist.

\section{References}

1. Chen M, Fuqua J, Eugster EA: Characteristics of referrals for gender dysphoria over a 13-year period. J Adolesc Health 2016;58:369-371.

2. Costa R, Colizzi M: The effect of cross-sex hormonal treatment on gender dysphoria individuals' mental health: A systematic review. Neuropsychiatr Dis Treat 2016;12:1953-1966.

3. Ikeda K, Baba T, Noguchi H, et al.: Excessive androgen exposure in female-to-male transsexual persons of reproductive age induces hyperplasia of the ovarian cortex and stroma but not polycystic ovary morphology. Hum Reprod 2013;28:453-461.

4. Schulze C: Response of the human testis to long-term estrogen treatment: Morphology of Sertoli cells, Leydig cells and spermatogonial stem cells. Cell Tissue Res 1988;251:31-43.

5. Finlayson C, Johnson EK, Chen D, et al.: Proceedings of the working group session on fertility preservation for individuals with gender and sex diversity. Transgend Health 2016; 1:99-107.

6. Johnson EK, Finlayson C, Rowell EE, et al.: Fertility preservation for pediatric patients: Current state and future possibilities. J Urol 2017;198:186-194.

7. Nahata L, Chen D, Moravek MB, et al.: Understudied and under-reported: Fertility issues in transgender youth-A narrative review. J Pediatr 2019;205:265-271.

8. Coleman E, Bockting W, Botzer M, et al.: Standards of care for the health of transsexual, transgender, and gendernonconforming people, Version 7. Int $\mathbf{J}$ Transgend 2012; 13:165-232.

9. Hembree WC, Cohen-Kettenis PT, Gooren L, et al.: Endocrine treatment of gender-dysphoric/gender-incongruent persons: An Endocrine Society clinical practice guideline. J Clin Endocrinol Metab 2017;102:3869-3903.

10. Ethics Committee of the American Society for Reproductive Medicine: Access to fertility services by transgender persons: An Ethics Committee opinion. Fertil Steril 2015; 104:1111-1115.

11. Armuand GM, Wettergren L, Rodriguez-Wallberg KA, Lampic C: Desire for children, difficulties achieving a pregnancy, and infertility distress 3 to 7 years after cancer diagnosis. Support Care Cancer 2014;22:2805-2812.

12. Stein DM, Victorson DE, Choy JT, et al.: Fertility preservation preferences and perspectives among adult male survivors of pediatric cancer and their parents. J Adolesc Young Adult Oncol 2014;3:75-82.

13. Nilsson J, Jervaeus A, Lampic C, et al.: 'Will I be able to have a baby?' Results from online focus group discussions with childhood cancer survivors in Sweden. Hum Reprod 2014;29:2704-2711.

14. Nahata L, Tishelman AC, Caltabellotta NM, Quinn GP: Low fertility preservation utilization among transgender youth. J Adolesc Health 2017;61:40-44.

15. Chen D, Simons L, Johnson EK, et al.: Fertility preservation for transgender adolescents. J Adolesc Health 2017;61:120123.

16. Strang JF, Jarin J, Call D, et al.: Transgender Youth Fertility Attitudes Questionnaire: Measure development in nonautistic and autistic transgender youth and their parents. J Adolesc Health 2018;62:128-135.

17. Chen D, Matson M, Macapagal K, et al.: Attitudes toward fertility and reproductive health among transgender and gender-nonconforming adolescents. J Adolesc Health 2018; 63:62-68.

18. Johnson EK, Rosoklija I, Shurba A, et al.: Future fertility for individuals with differences of sex development: Parent attitudes and perspectives about decision-making. J Pediatr Urol 2017;13:402-413.

19. Kyweluk MA, Sajwani A, Chen D: Freezing for the future: Transgender youth respond to medical fertility preservation. Int J Transgend 2018:1-16.

20. Dedoose Version 8.1.31. 2017. Available at www.dedoose .com Accessed January 30, 2019.

21. Guest G, MacQueen KM, Namey EE: Applied Thematic Analysis. Los Angeles, CA: Sage Publications, Inc., 2012.

22. Tong A, Sainsbury P, Craig J: Consolidated criteria for reporting qualitative research (COREQ): A 32-item checklist for interviews and focus groups. Int J Qual Health Care 2007;19:349-357.

23. Lincoln YS, Guba EG: Processing naturalistically-obtained data. In: Naturalistic Inquiry. Newbury Park, CA: Sage Publications, Inc., 1985.

24. Fleiss JL: Measuring nominal scale agreement among many raters. Psychol Bull 1971;76:378-382.

25. Chen D, Simons L: Ethical considerations in fertility preservation for transgender youth: A case illustration. Clin Pract Pediatric Psychol 2018;6:93-100.

26. Campo-Engelstein L, Chen D: Ethical issues in pediatric and adolescent fertility preservation. In: Pediatric and Adolescent Oncofertility. Edited by Woodruff TK, Gosiengfiao YC. Cham, Switzerland: Springer International Publishing, 2016, pp. 259-267.

27. Jones G, Hughes J, Mahmoodi N, et al.: What factors hinder the decision-making process for women with cancer and contemplating fertility preservation treatment? Hum Reprod Update 2017;23:433-457. 
28. Walter JR, Xu S, Woodruff TK: A call for fertility preservation coverage for breast cancer patients: The cost of consistency. J Natl Cancer Inst 2017;109. DOI: 10.1093/ jnci/djx006.

29. Cardozo ER, Huber WJ, Stuckey AR, Alvero RJ: Mandating coverage for fertility preservation-A step in the right direction. N Engl J Med 2017;377:1607-1609.

30. Gilbert K, Nangia AK, Dupree JM, et al.: Fertility preservation for men with testicular cancer: Is sperm cryopreservation cost effective in the era of assisted reproductive technology? Urol Oncol 2018;36:92.e1-e92.e9.

31. Canada AL, Schover LR: The psychosocial impact of interrupted childbearing in long-term female cancer survivors. Psychooncology 2012;21:134-143.

32. Light AD, Obedin-Maliver J, Sevelius JM, Kerns JL: Transgender men who experienced pregnancy after femaleto-male gender transitioning. Obstet Gynecol 2014;124: 1120-1127.

33. Ellis SA, Wojnar DM, Pettinato M: Conception, pregnancy, and birth experiences of male and gender variant gestational parents: It's how we could have a family. J Midwifery Womens Health 2015;60:62-69.
34. Light A, Wang LF, Zeymo A, Gomez-Lobo V: Family planning and contraception use in transgender men. Contraception 2018;98:266-269.

35. Schneider F, Neuhaus N, Wistuba J, et al.: Testicular functions and clinical characterization of patients with Gender Dysphoria (GD) undergoing sex reassignment surgery (SRS). J Sex Med 2015;12:2190-2200.

36. Ehrensaft D: Found in transition: Our littlest transgender people. Contemp Psychoanal 2014;50:571-592.

37. Nahata L, Quinn GP, Tishelman A: A call for fertility and sexual function counseling in pediatrics. Pediatrics 2016; 137:e20160180.

Address correspondence to:

Diane Chen, PhD

The Potocsnak Family Division of Adolescent and Young Adult Medicine

Ann \& Robert H. Lurie Children's Hospital of Chicago

225 E. Chicago Avenue, Box $161 B$

Chicago, IL 60611-2605

E-mail: dichen@luriechildrens.org 